\title{
Durability and Lifetime Prediction of Flax Fiber Reinforced Polymer Composites
}

\author{
Robert Chlela ${ }^{1}$, David Bigaud ${ }^{2}$, Hassen Riahi ${ }^{2}$, Marc Quiertant ${ }^{3}$, Laurence Curtil ${ }^{4}$, Karim \\ Benzarti ${ }^{1 *}$
}

\author{
${ }^{1}$ Lab Navier, Univ Gustave Eiffel, ENPC, CNRS, F-77447 Marne-la-Vallée, France \\ ${ }^{2}$ LARIS, UNIV Angers, SFR MathSTIC, 49000 Angers, France \\ ${ }^{3}$ MAST-EMGCU, Univ Gustave Eiffel, IFSTTAR, F-77447 Marne-la-Vallée, France \\ ${ }^{4}$ Université Lyon 1, LMC2, F-69622 Villeurbanne, France
}

*Karim Benzarti, karim.benzarti@univ-eiffel.fr

\begin{abstract}
Flax fiber reinforced polymer (FFRP) composites are demonstrating promising outcomes which makes them potential candidates to replace synthetic composites in various industrial applications. However, there is limited information regarding their long-term performance, and it is usually acknowledged that natural fibers are less resistant than their synthetic counterparts. In this context, it is crucial to study their durability before considering their use for structural rehabilitation and strengthening in construction. This study aims to investigate and predict the performance of FFRP composites with a bio-based epoxy matrix. The test program consisted in exposing FFRP laminates and FFRP strengthened concrete slabs to different accelerated ageing conditions over a total period of 2 years, and with various combinations of temperature and relative humidity in the ranges $20-60^{\circ} \mathrm{C}$ and $50-100 \% \mathrm{RH}$, respectively. Series of tensile, short beam and pull-off tests were periodically performed on ageing samples in order to evaluate their property evolutions over exposure time in the various environments. Finally, collected experimental data were analyzed using statistical tools, in view of developing a degradation model and evaluating the service lifetime performance of this new bio-based composite.
\end{abstract}

Keywords: Lifetime prediction, flax fiber-reinforced polymer composites, accelerated and natural ageing, tensile strength, adhesive bond.

\section{Introduction}

Flax fiber reinforced polymer (FFRP) composites offer both high mechanical properties to weight ratio and low carbon footprint, which makes them an environmentally friendly alternative to synthetic composites in specific industrial applications (Yan et al., 2014). However, a major challenge in using vegetal fibers remains their environmental sensitivity, especially when laminates are exposed to wet or moist service conditions (Le Duigou et al., 2010; Scida et al., 2013). Numerous studies from the literature have investigated the effect of humidity on the mechanical properties of FFRPs, but the prediction of the lifetime performance of these materials and the coupling effects of temperature/humidity on their ageing behavior are still matter of investigations.

In the field of civil engineering, it is crucial for engineers to get knowledge about the long-term performance of composite systems intended for structural strengthening, in addition to their short-term characteristics. This delayed behavior is highly dependent on the outdoor service conditions and can be affected by multiple factors, such as temperature, humidity, ultraviolet light exposure or alkalinity of concrete (Benzarti et al., 2011; Karbhari \& Abanilla, 2007; Quiertant et al., 2017; Houhou et al., 2014). This study is focused on the combined effects of temperature and humidity on the durability of unidirectional (UD) FFRP laminates produced by hand layup process, and on the durability of their adhesive bond with concrete as well (Chlela, 2019; Benzarti et al., 2018). An emphasis is placed on the influence of these two factors on the evolution over time of selected mechanical performance indicators (i.e., longitudinal tensile properties and interlaminar shear strength of the UD laminate, pull-off strength of the composite/concrete assembly) and on the development of a degradation model to predict these performance evolutions and the expected lifetime of the FFRP system. 


\section{Materials and methods}

\section{Materials and ageing conditions}

Unidirectional flax fiber/bio epoxy composites, consisting of 2 layers of $200 \mathrm{~g} / \mathrm{m}^{2}$ flax fiber fabrics, were manually prepared using the hand layup technique. The flax fiber fabrics used in this study were produced by Groupe Depestele, a French natural textile company. The epoxy resin (CHS-EPOXY G520) was supplied by Spolchemie, a Czech chemical company known for its environmentally-friendly products. This resin (30\% bio-based) was mixed with a $100 \%$ bio-based amine hardener in stoichiometric proportions. The final FFRP laminates had a fiber volume fraction of around $16 \%$ and were cured in the laboratory conditions $\left\{20^{\circ} \mathrm{C} / 35-50 \% \mathrm{RH}\right\}$ for 3 weeks until stabilization of the polymerization process.

In addition, FFRP reinforced concrete blocks were also prepared in view of performing adhesive bond tests. Concrete blocks were first cast using a ready-to-mix commercial mixture of compressive strength $50 \mathrm{MPa}$ at 28 days. The blocks were stored for 90 days before strengthening of the upper face with a single ply of UD flax fabric impregnated with the bio-epoxy matrix. As previously, a 3-week cure was achieved before starting exposure tests.

All these specimens (laminates and FFRP reinforced blocks) were then divided into 7 series that were placed in various environments, corresponding to either accelerated ageing conditions or outdoor climate conditions (see Table 1). During the test program, specimens were periodically removed from the ageing environments in order to be mechanically tested.

Table 1. Ageing conditions selected for the design of experiments

\begin{tabular}{cccc}
\hline Name & Temperature & Humidity & \multicolumn{1}{c}{ Test Schedule } \\
\hline V1 & $20^{\circ} \mathrm{C}$ & $50 \%$ RH (climatic chamber) & $3,6,12$ and 24 months \\
\hline V2 & $20^{\circ} \mathrm{C}$ & $100 \%$ (immersion in water) & $3,6,12$ and 24 months \\
\hline V3 & $60^{\circ} \mathrm{C}$ & $50 \%$ RH (climatic chamber) & $3,6,12$ and 24 months \\
\hline V4 & $40^{\circ} \mathrm{C}$ & $100 \%$ (immersion in water) & $3,6,12$ and 24 months \\
\hline V5 & $60^{\circ} \mathrm{C}$ & $75 \%$ RH (climatic chamber) & $3,6,12$ and 24 months \\
\hline V6 & $60^{\circ} \mathrm{C}$ & $100 \%$ (immersion in water) & $3,6,12$ and 24 months \\
\hline VN & Outdoor exposure in Lyon, France & 12 and 24 months \\
\hline
\end{tabular}

\section{Tensile testing procedure}

Tensile tests were carried out in the longitudinal direction of the FFRP laminates, following the procedure detailed in EN ISO 527 standard and French AFGC guidelines. Glass fiber composite tabs were glued to each extremity of the samples with an epoxy adhesive, in order to improve the grip during tensile tests. An Instron 5969 universal testing machine, equipped with a contact-free Advanced Video Extensometer (AVE), was used to apply the loading speed of $1 \mathrm{~mm} / \mathrm{min}$, as advised in the standard method. Instead of calculating a tensile strength considering the actual section of sample (which is very dependent on the quality of impregnation of the laminate), one determines a maximum tensile force (or tensile capacity) per unit width of fabrics according to the following equation (ASTM D7565/D7565M):

Maximum tensile force per unit width $(\mathrm{kN} / \mathrm{m})=\frac{\text { Force at failure }}{\text { sample }^{\prime} \mathrm{s} \text { width } \times \text { number of layers }}$

The tensile stiffness was determined by the slope of the curve (tensile force per unit width versus strain) between points of abscissa 0.3 and $0.5 \%$ strain:

Tensile stiffness $($ in $\mathrm{kN} / \mathrm{m})=\frac{\Delta \text { Applied tensile force }}{\Delta \text { strain }}$ 


\section{Short beam shear testing procedure}

Short beam 3-point-bending tests were carried out according to NF EN ISO 14130 standard. Small samples of FFRP laminates (2 layers) with base dimensions of $10 \mathrm{~mm} \times 20 \mathrm{~mm}$ were used for these tests. An Instron 5969 universal testing machine equipped with a 3 point-bending setup was used to apply the compressive loading speed of $1 \mathrm{~mm} / \mathrm{min}$ as advised in the standard method. To calculate the interlaminar shear strength $\tau$, the following equation was used:

Interlaminar shear strength $\tau=\frac{3}{4} \times \frac{\text { Failure load }}{\text { width } \times \text { thickness }}$

\section{Pull-off testing procedure}

Pull-off tests were performed according to EN 1542 / AFGC standards. The single FFRP layer reinforcing each concrete block was first drilled using a cylindrical core drill of diameter $50 \mathrm{~mm}$, until a depth of $4 \mathrm{~mm}$ was reached in the concrete substrate. A cylindrical steel disc of diameter $50 \mathrm{~mm}$ was then glued to the test zone using an epoxy adhesive. Finally, a tensile load was applied to the disc at constant speed of $0.05 \mathrm{MPa} / \mathrm{sec}$ using a Proceq DY-216 dynamometer until failure occurred, enabling the determination of the bond strength and failure mode.

\section{Experimental results}

Mechanical tests were first carried-out on unaged specimens, providing the initial reference performances for unaged specimens. Samples were then tested after 3, 6, 12 and 24 months ageing in the various conditions. Results are displayed in the graphs of Figure 1.

\section{Tensile properties}

Tensile tests performed on unaged FFRP samples provided reference values of $87.0 \pm 6.6 \mathrm{kN} / \mathrm{m}$ for the tensile capacity (ultimate load per unit width) and $7350 \pm 645 \mathrm{kN} / \mathrm{m}$ for the tensile stiffness per unit width. These reference values were used afterwards to normalize the residual performances of aged specimens. It is to note that a bilinear behaviour was observed for unaged FFRP specimens, but not for aged samples. Therefore only the stiffness (slope of the tensile curve) measured between points of abscissa 0.3 and $0.5 \%$ strain, common to both unaged and aged specimens, was considered here.

Figure 1.a and 1.b present respectively the (normalized) residual tensile capacities and stiffness obtained for FFRP laminates exposed to the various ageing environments for 3 to 24 months. It was found that:

- FFRP laminates exposed to $\left\{20^{\circ} \mathrm{C} ; 50 \% \mathrm{RH}\right\}$ and to outdoor conditions (VN) did not show significant degradation of their tensile properties over the 24 month-period,

- Samples exposed to elevated temperature $\left(60^{\circ} \mathrm{C}\right)$ at $50 \%$ and $75 \% \mathrm{RH}$, showed an initial increase in tensile capacity, due to the post-curing process of the bio-epoxy matrix (also confirmed by additional DSC analyses). Further exposure (from 12 to 24 months) resulted in a decreased tensile capacity, attributed to thermal degradations of both the flax fibers and the polymer matrix, as confirmed by FTIR analyses (Fourier Transform Infra-Red spectroscopy),

- Specimens immersed in water showed a $20-35 \%$ reduction in their tensile capacity after 24 months, with a kinetics that was dependent on the ageing temperature (the higher the temperature, the higher the degradation kinetics). The tensile stiffness was also severely affected, with a large decrease up to $40 \%$ after 24 months in immersion at $60^{\circ} \mathrm{C}$. This phenomenon is driven by an intense water absorption of flax fibers, which produces severe swelling effects that degrade the fiber/matrix interface and initiate micro-cracking of the polymer matrix, and by hydrolytic degradation of the flax fibers as well (dissolution of poorly crystallized components, like pectins and hemicellulose) (Scida, et al, 2013; Chlela, 2019)

These results suggest that immersion conditions are very severe compared to the other accelerated ageing conditions considered in this study, and to the outdoor exposure VN as well. Immersion also involves specific degradation mechanisms that may not be representative of actual ageing processes occurring in usual service conditions. 


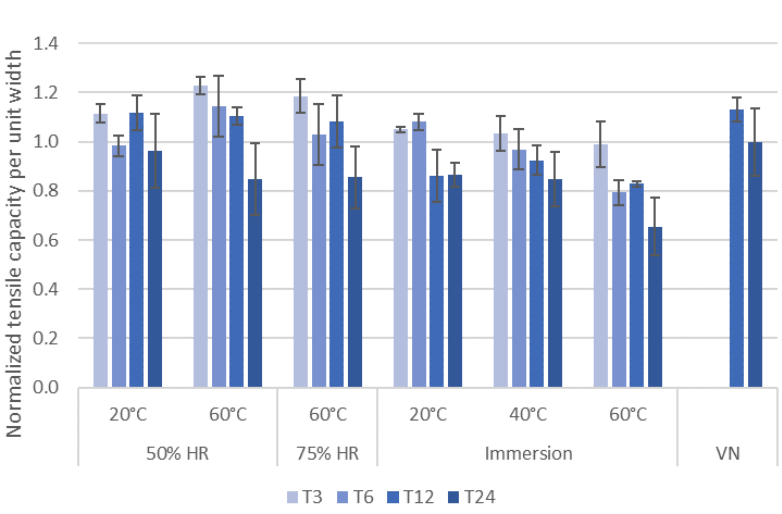

(a)

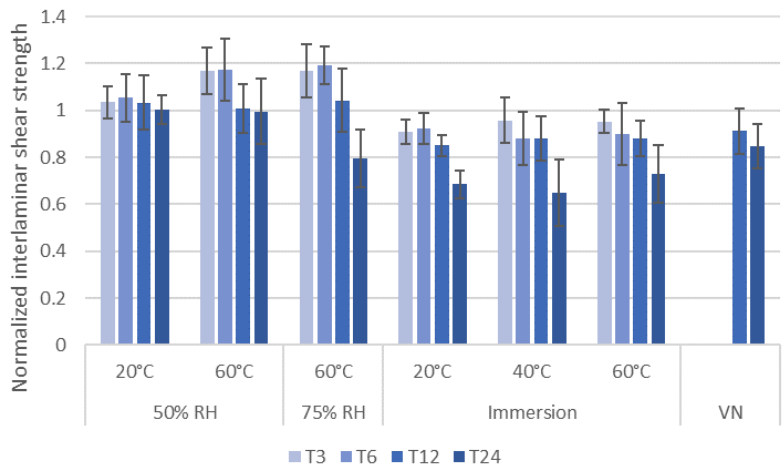

(c)

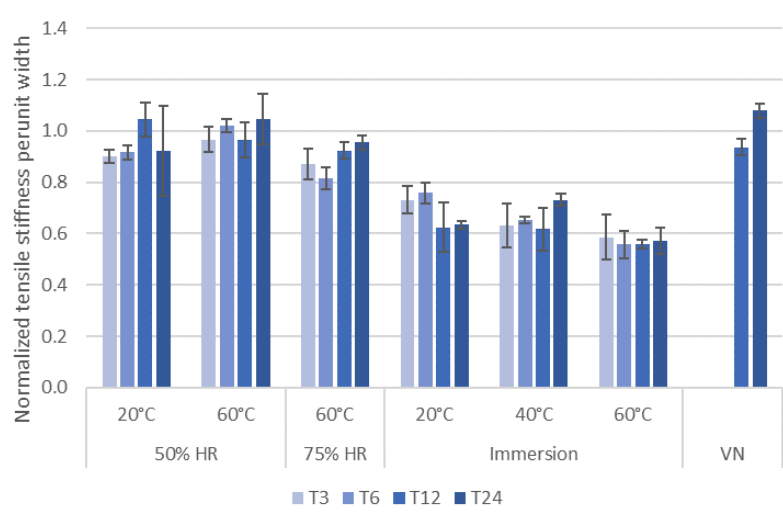

(b)

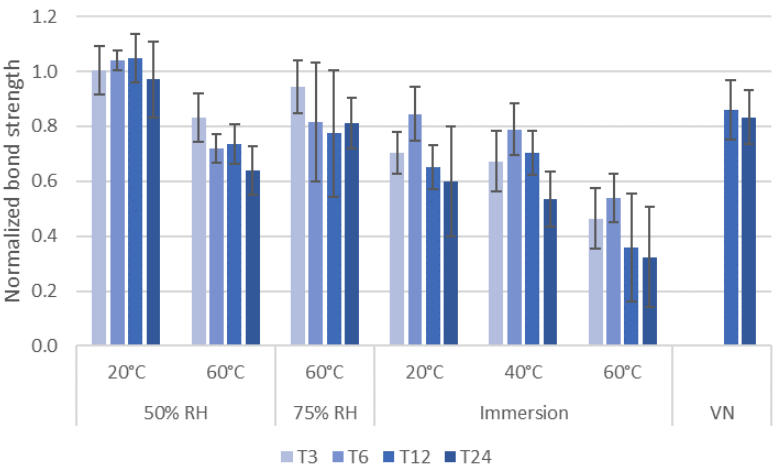

(d)

Figure 1. Normalized results of mechanical tests for specimens exposed to the various conditions for up to 24 months: (a) Tensile capacity per unit width (b) Tensile stiffness per unit width (c)

Interlaminar shear strength (d) Pull-off bond strength.

\section{Interlaminar shear properties}

Short beam shear tests were first carried-out on unaged FFRP coupons, providing a reference value of $8.5 \pm 0.8 \mathrm{MPa}$ for the initial interlaminar shear strength (ISS). Tests were then performed on aged specimens, and their residual properties were normalized by the reference value and reported in the graph of Figure 1.c. These results show that, like for the tensile capacity, no significant decrease in ISS of the laminate was observed under condition $\mathrm{V} 1$ at $\left\{20^{\circ} \mathrm{C} ; 50 \% \mathrm{RH}\right\}$. For specimens exposed at $60^{\circ} \mathrm{C}$ and $50-75 \% \mathrm{RH}$, an initial increase in ISS (post-curing effect) followed by a sharp decrease after 12 months exposure (thermal degradation) was reported. Specimens immersed in water at various temperatures showed once again large decrease in ISS (up to 65\%) due to severe degradations of the FFRP laminates. Differently, samples exposed to outdoor conditions over 24 months exhibited a limited decrease in ISS compared to the reference value ( 15- 20\%).

\section{Adhesive bond properties at the composite/concrete interface}

Pull-off tests performed on unaged FFRP reinforced concrete slabs, gave a reference value of the pulloff strength equal to $4.1 \pm 0.3 \mathrm{MPa}$, with a typical cohesive concrete failure as shown in Figure 2.a. After ageing, a significant decrease in bond strength was observed for all specimens, except for those subjected to $20^{\circ} \mathrm{C}-50 \% \mathrm{RH}$ (Figure 1.d). Samples directly immersed in water were the most affected, with a reduction up to $65 \%$ in the case of samples immersed at $60^{\circ} \mathrm{C}$. Such a degradation of the bond strength under wet conditions was accompanied by a change in failure mode, from an initial cohesive concrete failure towards a mixed (Figure 2.b) or FFRP debonding mode (Figure 2.c). This change in failure mode and the reduction in bond strength can both be attributed to the weakening of physicochemical bonds at the concrete/composite interface in presence of water.

Specimens exposed to outdoor conditions for 24 months also showed a reduction of their pull-off strength (around 20\%), together with a mixed failure mode similar to Figure 2.b. It suggests again that outdoor exposure is less severe than accelerated ageing by immersion in water. 
(a)

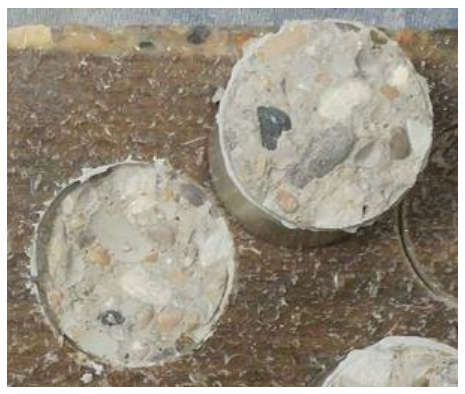

(b)

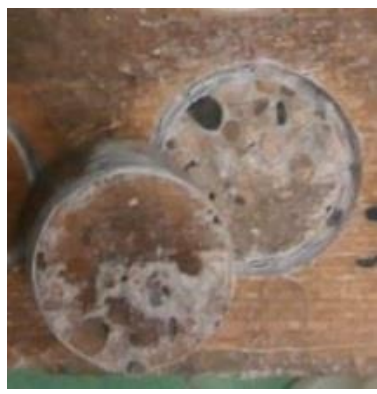

(c)

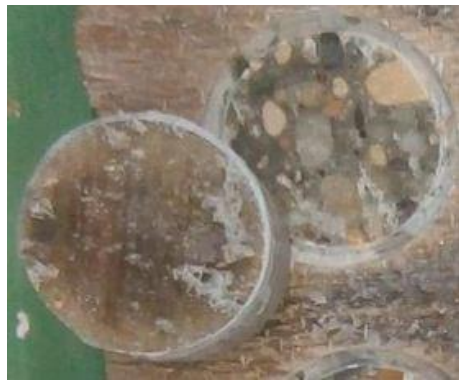

Figure 2. Failure modes: a) Cohesive concrete failure, b) Mixed failure, c) Debonding of the laminate

\section{Lifetime prediction}

Previous researchers have proved that the evolution of FRP performance can be expressed in the form of $\mathrm{P}(\mathrm{t})=\mathrm{A}+\mathrm{B} \times \ln (\mathrm{t})$ where $\mathrm{P}$ is the mechanical performance, $\mathrm{A}$ and $\mathrm{B}$ are constants, $\mathrm{t}$ is the time and In refers to Napierian logarithm (Karbhari \& Abanilla, 2007; Silva et al., 2014). However, in this study the objective is to introduce the temperature and the humidity in the model, and to take into account their coupling effect on the long-term performance of FFRP composites as well. Therefore, a specific degradation model was constructed as a function of temperature, humidity and time:

$\mathrm{P}(\mathrm{t}, \widetilde{T}, \widetilde{H})=R_{1}(\widetilde{T}, \widetilde{H})+R_{2}(\widetilde{T}, \widetilde{H}) \times A \times \ln (t)$

With: $\widetilde{T}=\frac{T-T_{\text {nominal }}}{T_{\text {nominal }}} \quad ; \quad \widetilde{H}=\frac{H-\text { nominal }}{H_{\text {nominal }}}$

Where $\mathrm{P}(\mathrm{t}, \widetilde{T}, \widetilde{H})$ is the performance at the considered time $\mathrm{t}$, temperature $\widetilde{T}$, and humidity $\widetilde{H}$; $\mathrm{A}$ is the degradation rate under a nominal condition chosen as $\left\{20^{\circ} \mathrm{C} ; 50 \% \mathrm{RH}\right\} ; R_{1}(\widetilde{T}, \widetilde{H})$ is a function that introduces the effect of post curing and $R_{2}(\widetilde{T}, \widetilde{H})$ is a function that links the degradation rate under different conditions to that in nominal condition $\left\{20^{\circ} \mathrm{C} ; 50 \% \mathrm{RH}\right\}$ :

$R_{1}(\widetilde{T}, \widetilde{H})=a_{1}+a_{T 1} \widetilde{T}+a_{H 1} \widetilde{H}+a_{T-H 1} \tilde{T} \widetilde{H}+a_{T T 1} \widetilde{T}^{2}+a_{H H 1} \widetilde{H}^{2}$

$R_{2}(\widetilde{T}, \widetilde{H})=1+a_{T 2} \widetilde{T}+a_{H 2} \widetilde{H}+a_{T-H 2} \widetilde{T} \widetilde{H}+a_{T T 2} \widetilde{T}^{2}+a_{H H 2} \widetilde{H}^{2}$

$R_{2}(\widetilde{T}, \widetilde{H})=\frac{\text { degradation rate }(\widetilde{T}, \widetilde{H})}{\text { degradation rate in nominal condition }}$

The primary and quadratic influence of temperature and humidity as well as their coupling are implemented in the $R_{1}(\widetilde{T}, \widetilde{H})$ and $R_{2}(\widetilde{T}, \widetilde{H})$ functions. The coefficients $\left(a_{1}, a_{T 1}, a_{H 1}, a_{T-H 1}, a_{T T 1}\right.$, $\left.a_{H H 1}, A, a_{T 2}, a_{H 2}, a_{T-H 2}, a_{T T 2}, a_{H H 2}\right)$ are calculated from experimental data using nonlinear regressions. Their values determined for the various performance indicators are reported in Table 2.

Table 2 Coefficients of the degradation model identified for the various performance indicators

\begin{tabular}{ccccc}
\hline & $\begin{array}{c}\text { Tensile capacity } \\
\text { per width unit }\end{array}$ & $\begin{array}{c}\text { Tensile stiffness per } \\
\text { width unit }\end{array}$ & $\begin{array}{c}\text { Interlaminar shear } \\
\text { strength }\end{array}$ & Bond Strength \\
\hline $\boldsymbol{a}_{\mathbf{1}}$ & 1.255 & 1 & 1.1238 & 1 \\
\hline $\boldsymbol{a}_{\boldsymbol{T} \mathbf{1}}$ & 2.625 & 0 & 8.0877 & 0 \\
\hline $\boldsymbol{a}_{\boldsymbol{H} \mathbf{1}}$ & 0.2217 & 0 & 2.502 & 0 \\
\hline $\boldsymbol{a}_{\boldsymbol{T}-\boldsymbol{H} \mathbf{1}}$ & -6.3372 & 0 & -3.9915 & 0 \\
\hline $\boldsymbol{a}_{\boldsymbol{T} \mathbf{1}}$ & 24.974 & 0 & -31.4266 & 0 \\
\hline $\boldsymbol{a}_{\boldsymbol{H} \mathbf{1}}$ & 0.0904 & 0 & -2.1776 & 0 \\
\hline $\boldsymbol{A}$ & -0.0352 & -0.0085 & -0.0165 & -0.0004 \\
\hline $\boldsymbol{a}_{\boldsymbol{T} \mathbf{2}}$ & 3.5954 & -29.1 & 87.6979 & -4472.7 \\
\hline $\boldsymbol{a}_{\boldsymbol{H} \mathbf{2}}$ & 0.0051 & -3.117 & 25.97 & -3288.1 \\
\hline $\boldsymbol{a}_{\boldsymbol{T}-\boldsymbol{H} \mathbf{2}}$ & -26.0112 & 24.123 & -40.5747 & -517.2 \\
\hline $\boldsymbol{a}_{\boldsymbol{T} \mathbf{2}}$ & 190.4839 & 154.74 & -371.6323 & 9647.3 \\
\hline $\boldsymbol{a}_{\boldsymbol{H} \mathbf{2}}$ & 2.1297 & 8.845 & -20.3741 & 4622.5 \\
\hline
\end{tabular}


The predicted evolutions of the mechanical indicators are displayed in Figure 3. It is crucial to note that, by modelling the mechanical performance as a function of $\ln (\mathrm{t})$, we force the values to strictly decrease with time. In reality, experiments have shown that there is an initial increase in several performance indicators (tensile capacity and ISS) over the 3 first months, due to post-curing of the polymer matrix, especially in high temperature environments. Consequently, simulated evolutions of the tensile capacity and ISS in the time interval 0-3 months should not be considered representative, and the corresponding parts were plotted in dashed lines on curves of Figure 3.a and 3.c. Differently, experiments showed that both tensile stiffness and bond strength are not influenced by the post-curing process (we do not observe any initial increase for these properties in Fig. 1 and the trends remain strictly decreasing). The model gives thus a good description of these properties over the entire time interval, as coefficients relating the influence of $\mathrm{T}$ and $\mathrm{H}$ on the intercept of the function $R_{1}(\widetilde{T}, \widetilde{H})$ are assumed equal to 0 (see Table 2 ).

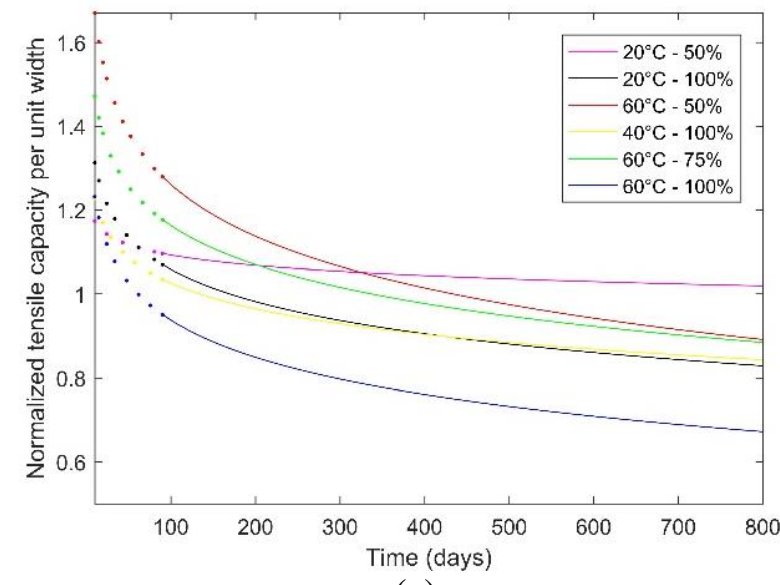

(a)

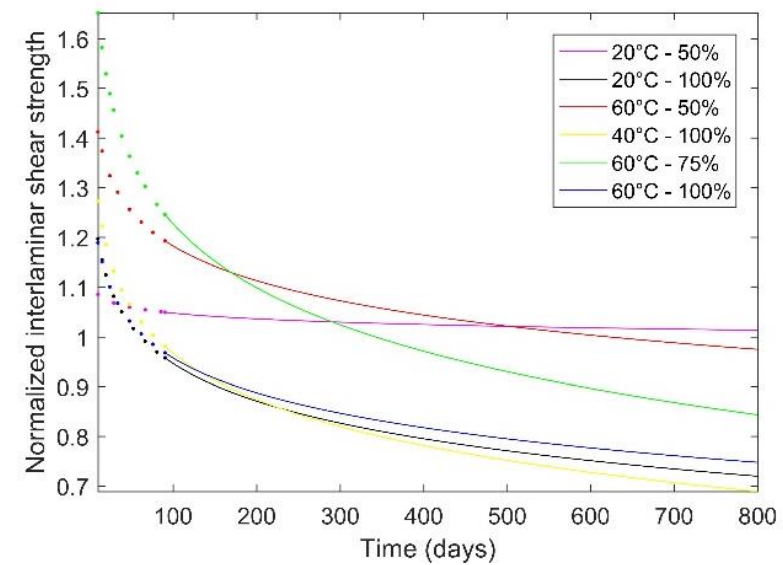

(c)

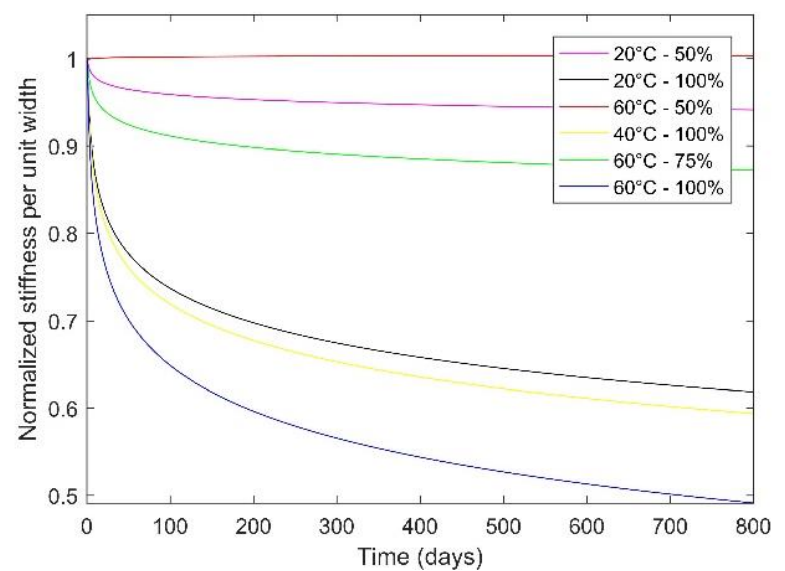

(b)

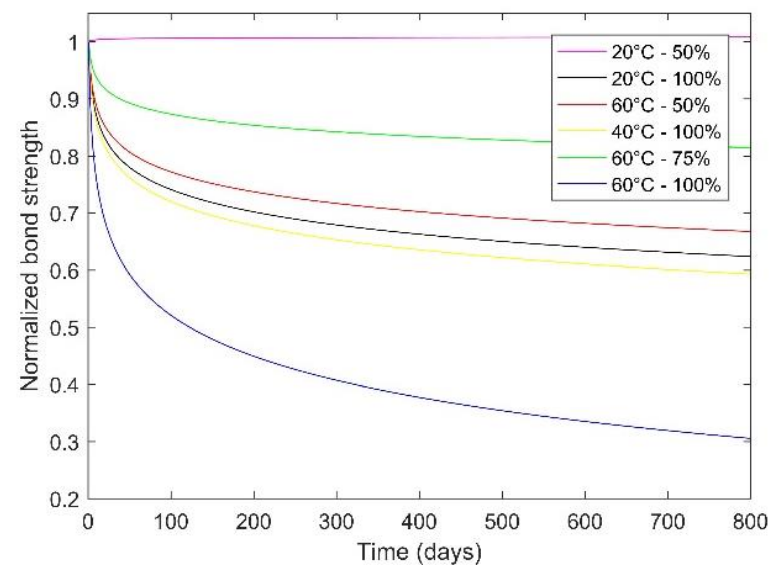

(d)

Figure 3. Predicted evolutions of mechanical performance indicators for FFRP laminates exposed in various accelerated environments: (a) Tensile strength (b) Tensile stiffness (c) Interlaminar Shear Strength (d) Bond strength of the concrete/composite interface

To go further and predict the lifetime of FFRP laminates and their adhesive bond with concrete, it is then necessary to establish an end-of-life criterion that should be considered to ensure safe functioning of the FRP strengthening system (minimal allowable performance). In accordance with Abanilla et al (2005), the design value prescribed by ACI 440.2R-17 was chosen as the end of life criterion. Minimum allowable performances $f_{f u}$ were thus calculated according to Equations (9) and (10), based on the mean experimental values $\overline{f_{f u}^{*}}$ and standard deviations $\sigma$ determined for unaged specimens, and on an environmental knockdown factor $C_{E}$ that depends on the type of FRP material and the type of environment. As no specification is available for flax fiber composites in the current code, the value $C_{E}$ $=0.65$ prescribed for glass fiber composites subjected to outdoor exposure conditions was retained. 
$f_{f u}=C_{E} \times f_{f u}^{*}$

$f_{f u}^{*}=\overline{f_{f u}^{*}}-3 \sigma$

After calculation of the minimum allowable values of the various performance indicators, the previous degradation model was used to estimate the time needed to reach these lower limits. Theoretical lifetimes are reported in Table 3, based on the simulated evolutions of the various performance indicators.

As expected, FFRP laminates immersed in water (conditions V2, V4 and V6) show much shorter lifetimes compared to non-immersed samples. In addition, the bond strength seems to be the most critical performance indicator, as it provides the shortest lifetimes in most accelerated ageing environments.

Table 3. Lifetime prediction under various ageing conditions

\begin{tabular}{cccccc}
\cline { 2 - 5 } & & \multicolumn{4}{c}{ Performance Indicators } \\
\cline { 2 - 5 } & & $\begin{array}{c}\text { Tensile } \\
\text { capacity }\end{array}$ & $\begin{array}{c}\text { Tensile } \\
\text { stiffness }\end{array}$ & ISS & $\begin{array}{c}\text { Bond } \\
\text { strength }\end{array}$ \\
\hline Mean reference value & $87.0 \mathrm{kN} / \mathrm{m}$ & $7350 \mathrm{kN} / \mathrm{m}$ & $8.5 \mathrm{MPa}$ & $4.10 \mathrm{MPa}$ \\
\hline Standard deviation & $6.6 \mathrm{kN} / \mathrm{m}$ & $645 \mathrm{kN} / \mathrm{m}$ & $0.8 \mathrm{MPa}$ & $0.25 \mathrm{MPa}$ \\
\hline $\begin{array}{c}\text { Minimum allowable performances } \\
(=\text { end-of-life criterion) }\end{array}$ & $43.6 \mathrm{kN} / \mathrm{m}$ & $3519 \mathrm{kN} / \mathrm{m}$ & $3.97 \mathrm{MPa}$ & $2.17 \mathrm{MPa}$ \\
\hline \multirow{2}{*}{$\begin{array}{c}\text { Time to reach } \\
\text { (in years) }\end{array}$} & $\mathrm{V} 1$ & $>100$ & $>100$ & $>100$ & $>100$ \\
\cline { 2 - 6 } & $\mathrm{V} 2$ & 43 & 25 & 22 & 12 \\
\cline { 2 - 6 } & $\mathrm{V} 3$ & 20 & $>100$ & $>100$ & 34 \\
\cline { 2 - 6 } & $\mathrm{V} 4$ & 10 & 14 & 11 & 6 \\
\cline { 2 - 6 } & $\mathrm{V} 5$ & 39 & $>100$ & 17 & $<0.25$ \\
\hline
\end{tabular}

\section{Conclusion}

A lifetime prediction approach was proposed in this paper, based on a degradation model that was calibrated from a comprehensive experimental test program.

In a first experimental part, FFRP laminates and FFRP strengthened concrete blocks were subjected to various accelerated ageing conditions and their mechanical performances (tensile properties. ISS and adhesive bond strength with concrete) were monitored over a period of 24 months. Extensive degradations were observed for FFRP samples immersed in water, leading to large reduction in mechanical performances. The tensile capacity showed decreases up to $20 \%$ whereas the tensile stiffness was more severely affected with decreases up to $40 \%$ compared to unaged reference specimens. FFRP/concrete interface was also negatively affected by the presence of water. A decrease in bond strength was observed as well as a change in failure mode from a cohesive concrete failure to a debonding of the FFRP laminate. Regarding samples subjected to natural ageing in outdoor environment, only limited variations of mechanical performances were observed after 2 years of exposure. Globally, the outdoor exposure condition was found much less severe than the other accelerated ageing environments considered in this study.

In the second part, a degradation model was constructed to describe performance evolutions of the FFRP laminate and the concrete/composite interface in the accelerated ageing environments, based on a mathematical treatment of collected experimental data. This quadratic model takes into account the influence of temperature and humidity, as well as their combined effect. It was applied to predict the lifetimes of FFRP composites subjected to different ageing conditions, by assessing the time necessary to reach an imposed (arbitrary) end-of-life criterion corresponding to $15 \%$ maximum degradation on the mechanical performances. Results showed that the adhesive bond strength between the FFRP and concrete is the most affected indicator and governs the lifetime of the composite. 
Alternative modelling approaches are currently under development, based on a physical description of the influences of $\mathrm{T}$ and $\mathrm{H}$ on the mechanical performance rather than on pure mathematical treatment of experimental data, and on reliability assessment as well (Chlela, 2019; Yan et al, 2021).

\section{Acknowledgments}

Authors wish to acknowledge the National French Research Agency (ANR) for funding the MICRO project (contract ANR-15-CE22-0007-04- MICRO).

\section{References}

Abanilla MA, Li Y \& Karbhari VM (2005) Durability characterization of wet layup graphite/epoxy composites used in external strengthening. Composites Part B: Engineering, 37(2-3): 200-212.

Benzarti K, Chataigner S, Quiertant M, Marty C \& Aubagnac C (2011) Accelerated ageing behaviour of the adhesive bond between concrete specimens and CFRP overlays. Construction and Building Materials 25(2): 523-538.

Benzarti K, Chlela R, Zombré W, Quiertant M \& Curtil L (2018) Durability of flax/bio-based epoxy composites intended for structural strengthening. MATEC Web of Conferences 199: 07014. doi: $10.1051 /$ matecconf/201819907014.

Bigaud D, \& Ali O (2014) Time-variant flexural reliability of RC beams with externally bonded CFRP under combined fatigue-corrosion actions. Reliability Engineering \& System Safety 131: 257-270.

Chlela R (2019) Durabilité d'un système composite biosourcé (matrice époxy-fibres de lin) pour applications de renforcement structural : Approches expérimentale et fiabiliste. PhD thesis, University Paris-Est, France. In French. Available at: https://tel.archives-ouvertes.fr/tel-02894653/document

Houhou N, Benzarti K, Quiertant M, Chataigner S, Fléty A \& Marty C (2014) Analysis of the nonlinear creep behavior of concrete/FRP-bonded assemblies. Journal of Adhesion Science and Technology 28(14-15): 1345-1366.

Karbhari VM \& Abanilla MA (2007) Design factors, reliability, and durability prediction of wet layup carbon/epoxy used in external strengthening. Composites Part B: Engineering 38(1): 10-23.

Le Duigou A, Davies P \& Baley C (2010) Interfacial bonding of Flax fiber/Poly(l-lactide) biocomposites. Composites Science and Technology 70(2): 231-239.

Quiertant M, Benzarti K, Schneider J, Landrin F, Landrin M \& Boinski F (2017) Effects of Ageing on the Bond Properties of Carbon Fiber Reinforced Polymer/Concrete Adhesive Joints: Investigation Using a Modified Double Shear Test. Journal of Testing and Evaluation 45(6): 1920-1932.

Scida D, Assarar M, Poilâne C \& Ayad R (2013) Influence of hygrothermal ageing on the damage mechanisms of flax-fiber reinforced epoxy composite. Composites Part B: Engineering 48: 51-58.

Silva MAG, da Fonseca BS \& Biscaia H (2014) On estimates of durability of FRP based on accelerated tests. Composite Structures. 116(1): 377-387.

Yan L, Chouw N \& Jayaraman K (2014) Flax fiber and its composites - A review. Composites Part B: Engineering 56: 296-317. doi:10.1016/j.compositesb.2013.08.014

Yan W, Riahi H, Benzarti K, Chlela R, Curtil L \& Bigaud D (2021) Lifetime prediction of flax fiber reinforced composites using Tweedie Exponential Dispersion Degradation process. Mathematical Problems in Engineering 2021: 6629637 